\title{
(RE)VISITANDO CONCEITOS DE INFÂNCIA E EDUCAÇÃO
}

\section{(RE)VISITING CONCEPTS OF CHILDHOOD AND EDUCATION}

\author{
(RE)VISANDO CONCEPTOS DE INFANCIA Y EDUCACIÓN
}

\author{
Esméria de Lourdes Saveli* \\ Maria Odete Vieira Tenreiro** \\ Marta Maria Gonçalves Balbé Pires"**
}

\begin{abstract}
Resumo: O presente texto discute o conceito de infância, criança e educação em uma dimensão histórico-cultural. Reconhece que o conceito de infância e criança é um constructo social, fruto de um processo histórico atrelado às diferentes formas de organização da sociedade. Dessa maneira, não há como desvencilhar o conceito de criança e infância do âmbito social, uma vez que tais conceitos são coletivos e interconectados com seus contextos, com sua cultura, com sua história. Historicamente, a alteração desse conceito significou a alteração das instituições escolares. As discussões teóricas estão fundamentadas nos estudos de Heywood (2004), Philippe Ariès (1973), Postman (1999) e Rousseau (1973). O artigo resgata as concepções rousseaunianas que permearam o pensamento de Pestalozzi e de Fröbel, que criou o Kindergarten, uma espécie de jardim de infância que primava pela liberdade das crianças no processo de aprendizagem. Reconhece a importância dos trabalhos de Decroly, Montessori e Freinet como contribuições para a consolidação de novos conceitos sobre infância, criança e escola.
\end{abstract}

Palavras-chave: Educação. Criança. Infância.

Abstract: This paper discusses the concept of childhood, child and education in a historical and cultural dimension. It recognizes that the concept of childhood and child is a social construct, the result of a historical process linked to different forms of social organization. Thus, there is no way to disentangle the concept of childhood and children from the social aspect, since such concepts are collective and interconnected with their contexts, with their culture, with their history. Historically, the change of this concept meant changing school institutions. Theoretical discussions are based on studies by Heywood (2004), Philippe Ariès (1973), Postman (1999) and Rousseau (1973). This article presents views by Rousseau that permeated ideas by Pestalozzi and Fröbel, who created the "Kindergarten", a kind of kindergarten that sought to give children freedom in the learning process. It recognizes the importance of the work by Decroly, Montessori and Freinet as contributions to the consolidation of new concepts on childhood, child and school.

Keywords: Education. Children. Childhood.

\footnotetext{
* Doutora em Educação pela Unicamp. Professora associada do Programa de Pós-Graduação em Educação da UEPG. Correio eletrônico: esaveli@yahoo.com.br.

** Doutora em Educação pela PUC-SP. Professora da UEPG. Correio eletrônico: motenreiro@yahoo.com.br.

*** Doutora em Educação pela PUC-SP. Professora da Faculdade Adventista Paranaense. Correio eletrônico: marta.balbe@usb.org.br.
} 
Resumen: El presente texto discute el concepto de infancia, niño y educación en una dimensión histórico-cultural. Reconoce que el concepto de infancia y niño es un constructo social, fruto de un proceso histórico vinculado a los distintos modos de organización de la sociedad. De esta manera, no hay como disociar el concepto de niño e infancia del ámbito social, ya que tales conceptos son colectivos y están interconectados con sus contextos, con su cultura, con su historia. Históricamente, la modificación de este concepto significó la modificación de las instituciones escolares. Las discusiones teóricas están fundamentadas en los estudios de Heywood (2004), Philippe Ariès (1973), Postman (1999) y Rousseau (1973). El artículo rescata las concepciones rousseaunianas que pasan por el pensamiento de Pestalozzi y de Fröebel, quien creó el Kindergarten, una suerte de jardín de infancia que primaba por la libertad de los niños en el proceso de aprendizaje. Reconoce la importancia de los trabajos de Decroly, Montessori y Freinet como aportes para la consolidación de nuevos conceptos acerca de infancia, niño y escuela.

Palabras clave: Educación. Niño. Infancia.

\section{Explicitando conceitos}

A infância é um conceito social que se altera historicamente no interior de uma mesma sociedade. É objeto de transformação, em função de variáveis sociais como a classe social, o grupo étnico, entre outros. Dessa forma, o conceito de infância está diretamente relacionado às formas de organização social, ou seja, diferentes classes sociais produzem papéis distintos à criança (SARMENTO, 2001).

Na mesma direção desse conceito está o pensamento de Heywood (2004, p.21), para quem "a criança é um constructo social que se transforma com o passar do tempo e, não menos importante, varia entre grupos sociais e étnicos dentro de qualquer sociedade". Isso quer dizer que a concepção de infância que temos hoje é fruto de um processo histórico e que a criança que temos em nossas escolas é fruto da pós-modernidade, com características próprias da cultura na qual está inserida e do contexto histórico da qual faz parte. Etimologicamente, a palavra "infância" tem suas raízes no latim, infans, "ausência de fala”. Nas palavras de Castello e Mársico (2007, 52-53),

Um indivíduo de pouca idade é denominado infans. Esse termo está formado por um prefixo privativo in e fari, "falar", daí seu sentido de "que não fala", "incapaz de falar”. Tão forte é seu sentido originário que Lucrécio emprega ainda o substantivo derivado infantia com o sentido de "incapacidade de falar". Porém, logo infans substantivado e infantia são empregados no sentido de "infante", "criança" e "infância", respectivamente. De fato, é desse sentido que se geram os derivados e compostos, todos de época imperial, como infantilis, "infantil"; infanticidium, "infanticídio" etc. [...]. Em geral, infans podia designar criança em idade muito mais avançada que aquela em que "não falam", de modo que essa denominação é usual para as crianças até os sete anos [...] $\mathrm{Na}$ verdade, são encontrados usualmente usos de infans referindo-se a pessoas que se aproximam inclusive dos 13 ou 15 anos. Então, podemos entender que infans não remete especificamente à criança pequena que não adquiriu ainda a capacidade de falar, mas se refere aos que, por sua minoridade, não estão ainda habilitados para testemunhar nos tribunais: infans é assim "o que não se pode valer de sua palavra para dar testemunho".

Não há como desvencilhar os conceitos de criança e infância do âmbito social. Criança e infância são coletivos interconectados com seus contextos, com sua cultura, 
com sua história. Segundo Redin (2007, p.7), "são vítimas e protagonistas de uma complexa teia de relações trágicas definidas por opções políticas e educacionais diferenciadas".

$\mathrm{Na}$ Antiguidade, os gregos não se preocupavam muito com a infância como fase de desenvolvimento humano singular. Postman (1999) afirma que, entre os gregos, o infanticídio era uma prática legal e moral, embora alguns acreditassem que deveria haver limites impostos a essa cruel tradição. A iconografia sobrevivente da Antiguidade é limitada e não nos dá uma fonte fiel para que possamos analisar o retrato das crianças naquela época. Entretanto, o referido autor afirma que "das estátuas remanescentes, nenhuma é de criança” (p.20).

Philippe Ariès (1973), em sua obra História social da criança e da família, assegura que a infância foi (re)descoberta apenas no século XVII. Segundo o autor, a iconografia da Idade Média ignora a presença das crianças na sociedade e, quando raramente as retrata, o faz como se fossem adultos em miniatura. São palavras do autor:

Até por volta do século XII, a arte medieval desconhecia a infância ou não tentava representá-la. É difícil crer que essa ausência se devesse à incompetência ou à falta de habilidade. É mais provável que não houvesse lugar para a infância nesse mundo. [...] No mundo das fórmulas românticas, e até o fim do século XII, não existem crianças caracterizadas por uma expressão particular, e sim homens de tamanho reduzido (ARIÈS, 1973, p.50-1).

Outro argumento apresentado pelo autor para fundamentar a inexistência de uma preocupação específica com a infância era o fato de não existirem roupas diferentes para adultos e crianças. Segundo Ariès (1973, p.70), "a Idade Média vestia indiferentemente todas as classes de idade, preocupando-se apenas em manter visíveis através da roupa os degraus da hierarquia social. Nada no traje medieval separava a criança do adulto".

Somente a partir do século XVI haveria alguma distinção entre as roupas de criança e as de adulto. Porém, essa diferenciação ficava restrita aos meninos das camadas mais altas da sociedade. De acordo com Ariès (1973, p.78-9),

É curioso notar também que a preocupação em distinguir a criança se tenha limitado principalmente aos meninos [...], como se a infância separasse menos as meninas dos adultos do que os meninos. [...] Sem uma escolaridade própria, as meninas eram muito cedo confundidas com as mulheres, como outrora os meninos eram confundidos com os homens, e ninguém pensava em tornar visível através do traje uma distinção que começava a existir concretamente para os meninos, mas que ainda continuava inútil no caso das meninas.

No que diz respeito à diferenciação pelo traje, o autor conclui:

O sentimento da infância beneficiou primeiro os meninos, enquanto as meninas persistiram mais tempo no modo de vida tradicional que as confundia com os adultos. [...] O que é certo é que isso [a particularização da infância] aconteceu apenas nas famílias burguesas ou nobres. A criança do povo, os filhos dos camponeses e dos artesãos [...] continuaram a usar o mesmo traje dos adultos [...]. Elas conservaram o antigo modo de vida que não separava as crianças dos adultos, nem através do traje, nem através do trabalho, nem através dos jogos e brincadeiras (ARIÈS, 1973, p.81).

Para argumentar sobre a inexistência da infância até o início da Modernidade, Ariès mostra que as crianças não só conheciam os "segredos" dos adultos, como 
também participavam inclusive de jogos eróticos. Para fundamentar sua teoria, o autor utiliza o diário do médico do Rei Luis XIII durante a sua infância, o qual nos fala “[...] da liberdade com que se tratavam as crianças, da grosseria das brincadeiras e da indecência dos gestos cuja publicidade não chocava ninguém e que, ao contrário, pareciam perfeitamente naturais" (ARIÈS, 1973, p.125).

A prática familiar na qual as crianças participavam das brincadeiras sexuais dos adultos, segundo Ariès (p.128), "não se limitava somente à corte, mas fazia parte também do cotidiano das famílias de fidalgos e plebeus. Além disso, era prática comum segundo os costumes da época e não escandalizava ninguém”. Durante a Idade Média, esse distanciamento entre as crianças e os segredos dos adultos não existia.

O autor observa que, ainda no início do século XVII,

[...] se permitia, com a consciência limpa e publicamente, gestos e contatos físicos que só passavam a ser proibidos quando a criança atingia a puberdade, ou seja, praticamente, o mundo dos adultos. Isso acontecia por duas razões. Primeiro, porque se acreditava que a criança impúbere fosse alheia e indiferente à sexualidade. Portanto, os gestos e as alusões não tinham consequência sobre a criança, tornavam-se gratuitos e perdiam sua especificidade sexual - neutralizavam-se. Segundo, porque ainda não existia o sentimento de que as referências aos assuntos sexuais, mesmo que despojadas na prática de segundas intenções equívocas, pudessem macular a inocência infantil - de fato ou segundo a opinião que se tinha dessa inocência. $\mathrm{Na}$ realidade, não se acreditava que essa inocência realmente existisse. (ARIÈS, 1973, p.132).

Em uma sociedade oral, onde adultos e crianças compartilhavam os mesmos espaços, os mesmos jogos e brincadeiras, os mesmos brinquedos e mesmos contos de fada, o limite entre a infância e a idade adulta se perdia. As crianças tinham acesso a praticamente todas as formas de comportamento comuns à cultura. Na visão de Postman (1999, p.31), "A ideia de esconder os impulsos sexuais era estranha aos adultos, e a ideia de proteger as crianças dos segredos sexuais, desconhecida”. Postman autor conclui:

[...] as pinturas coerentemente retratavam as crianças como adultos em miniatura, pois logo que as crianças deixavam de usar cueiros, vestiam-se exatamente como outros homens e mulheres de sua classe social. A linguagem de adultos e crianças também era a mesma. [...] E por isso a maioria das crianças não frequentava a escola, já que não havia nada importante para lhes ensinar; a maioria era mandada embora de casa para fazer trabalhos subalternos ou servir como aprendizes. No mundo medieval a criança é, numa palavra, invisível. (POSTMAN, 1999, p. 33).

Essa "invisibilidade" da infância sobre a qual discorre Postman pode ser explicada também por meio da "incapacidade de sobrevivência das crianças" (1999, p.31). Devido às grandes taxas de mortalidade infantil, a sociedade medieval considerava a infância como uma fase de transição, que não merecia grande interesse. Para Ariès (1975, p. 52), “os homens dos séculos X-XI não se detinham diante da imagem da infância [...] esta não tinha para eles interesse, nem mesmo realidade. [...] A infância era um período de transição, logo ultrapassado, e cuja lembrança também era logo perdida".

Contudo, já a partir do século XII, começa a haver uma mudança nesse sentimento de estranhamento e afastamento da infância. Ariès (1975, p.65) comenta: 


\begin{abstract}
A descoberta da infância começou sem dúvida no século XIII, e sua evolução pode ser acompanhada na história da arte e da iconografia dos séculos XV e XVI. Mas os sinais de seu desenvolvimento tornaram-se particularmente numerosos e significativos a partir do fim do século XVI e durante o século XVII.
\end{abstract}

O mesmo autor nos fala de uma mudança no tratamento das mães e amas para com as crianças, à qual denomina "paparicação". Esse seria a primeiro momento de percepção da criança na família. Por sua vez, Heywood aponta que a criança era vista como um instrumento de distração e entretenimento para os adultos, e estes se deleitavam "com sua doçura, simplicidade e gracejos” (2004, p.33).

A transição da Idade Média para a Modernidade veio acompanhada de inúmeras mudanças, que vão contribuir para a reestruturação do sentimento de infância.

\section{Infância e educação}

A história da educação revela que os atenienses fundaram muitas escolas, algumas das quais se tornaram veículos de disseminação da cultura grega em muitos lugares do mundo. Havia ginásios, colégios de efebos, escolas de retórica, e até escolas elementares, onde eram ensinadas leitura e aritmética para crianças e jovens de idades variadas.

A preocupação grega com a escolarização de suas crianças e jovens não representa que a concepção grega de infância era semelhante à nossa. Os gregos, famosos por terem em sua língua uma palavra para tudo, não tinham uma que significasse criança. Além disso, na sociedade contemporânea, os métodos utilizados para disciplinar e educar nas escolas gregas poderiam ser considerados como maus tratos e até mesmo tortura. Conforme Postman (1999, p.22), Platão exemplifica bem essa situação ao afirmar em Protágoras que, para endireitar crianças desobedientes, eram necessárias "ameaças e pancadas, como se tratasse de um pedaço de pau torto".

Ainda na Antiguidade, os romanos superaram os gregos na compreensão do que fosse a infância. Embora tivessem emprestado deles a noção de escolarização, eles a ampliaram, já que passaram a estabelecer uma conexão entre a criança em crescimento e a noção de vergonha.

Segundo Postman (1999), a transformação que ocorreu no modo de pensar a infância no início da Idade Média se deve a três fatores: o desaparecimento da capacidade de ler e escrever, o desaparecimento da educação e o desaparecimento da vergonha. Quando se fala em desaparecimento da capacidade de ler e escrever, não se quer dizer que isso aconteceu para todos. No entanto, a alfabetização ficou restrita a uma quantidade tão pequena de pessoas que essas se tornaram uma corporação privilegiada.

Com o desaparecimento da escrita, todas as interações sociais eram feitas por meio da tradição oral. As pessoas, adultos ou crianças, aprendiam aquilo que lhes era necessário, ouvindo, por exemplo, sermões, dramas sacros, poemas recitados e contos. Isso muda concretamente o modo de se pensar a infância.

A ausência da leitura e da escrita para grande parte das pessoas nos ajuda a entender o segundo fator que transforma o modo de pensar a infância: o desaparecimento da educação. Em uma sociedade "onde a biologia determina a competência em comunicação, não há necessidade de [...] escolas [primárias]" (POSTMAN, 1999, p.28).

Isso não quer dizer que não havia escola na Idade Média. Elas existiam, 
principalmente aquelas que eram ligadas à Igreja e, portanto, particulares. Entretanto, essas escolas não possuíam um currículo organizado e nem separavam conteúdos para adequar sua dificuldade à faixa etária capaz de aprendê-los. As classes também não eram divididas por idade e era muito comum crianças e adultos dividirem a mesma sala de aula. Postman (1999, p.29) afirma que:

[...] se um menino da Idade Média ia à escola, começava aos 10 anos de idade, provavelmente mais tarde. Vivia sozinho em alojamentos na cidade, longe da família. Considerava normal encontrar adultos de todas as idades na sua turma e não se julgava diferente deles. Certamente não descobria correspondência alguma entre as idades dos alunos e o que eles estudavam. Era constante a repetição de lições, já que novos alunos chegavam continuamente e não tinham ouvido o que o mestre tinha dito antes. Claro, não havia mulheres presentes, e logo que os alunos eram liberados da disciplina da sala de aula estavam livres para fazer o que quisessem do lado de fora.

Partindo dessa descrição, pode-se considerar que na Idade Média não havia qualquer concepção de desenvolvimento infantil e nenhuma percepção de escolarização como preparação para o mundo adulto.

E, por fim, reforçando as ideias de Áries, o terceiro fator apontado para o desaparecimento da infância é o desaparecimento da vergonha.

[...] uma das principais diferenças entre um adulto e uma criança é que o adulto conhece certas facetas da vida - seus mistérios, suas contradições, sua violência, suas tragédias - cujo conhecimento não é considerado apropriado para as crianças e cuja revelação indiscriminada é considerada vergonhosa. (POSTMAN, 1999, p.29).
A transição da Idade Média para a Modernidade veio acompanhada de inúmeras mudanças que vão contribuir para a reestruturação do sentimento de infância.

A partir do século XIV, o movimento humanista iniciou uma profunda reforma na sociedade europeia. A retomada dos valores da Antiguidade clássica e o estudo do grego e do latim permitiram que aquelas ideias que haviam sido enterradas pela Idade Média voltassem à tona e fossem reformuladas, de acordo com a nova sociedade que estava surgindo. $\mathrm{O}$ antropocentrismo trouxe uma nova visão de mundo, em que os seres humanos eram vistos como autores da própria história e responsáveis pela transformação da realidade.

Outra grande transformação ocorrida durante a Renascença foi o surgimento da imprensa. Por meio dela, as informações chegavam muito mais rapidamente a uma quantidade maior de pessoas. De acordo Gilmore (apud POSTMAN 1999, p.36), “A invenção da impressão com tipos móveis provocou a transformação mais radical nas condições de vida intelectual na história da civilização ocidental [...] Seus efeitos foram sentidos, mais cedo ou mais tarde, em todos os segmentos da atividade humana".

A imprensa era uma necessidade da Europa. Os europeus conheciam o fabrico do papel, possuíam um alfabeto e, embora grande parte da população fosse analfabeta, havia os copistas, que poderiam mergulhar outras pessoas no mundo das letras. Além disso, o interesse pela cultura clássica e as grandes descobertas científicas tinham sede de livros. Sem falar, ainda, das grandes navegações e dos descobrimentos que ansiavam por dar notícias (POSTMAN, 1999).

A invenção da imprensa foi tão importante e revolucionou de tal maneira a sociedade europeia que, a partir dela, o sentimento 
de infância foi reinventado. São palavras do autor:

O que aconteceu, simplesmente, foi que o Homem Letrado tinha sido criado. E, ao chegar, deixou para trás as crianças. Pois, no mundo medieval, nem os jovens nem os velhos sabiam ler e o seu interesse era o aqui e o agora [...] é por isso que não havia a necessidade da ideia da infância, porque todos compartilhavam o mesmo ambiente informacional e, portanto, viviam no mesmo mundo social e intelectual. Mas, quando a prensa tipográfica fez a sua jogada, tornou-se evidente que uma nova espécie de idade adulta tinha sido inventada. [...] Depois da prensa tipográfica, os jovens teriam que se tornar adultos e, para isso, teriam de aprender a ler, entrar no mundo da tipografia. E para realizar isso precisariam de educação. Portanto, a civilização europeia reinventou as escolas. $E$ ao fazê-lo, transformou a infância numa necessidade. (POSTMAN, 1999, p.50, grifo nosso).

Assim, a prensa tipográfica trouxe novamente à vida dois aspectos fundamentais que trazem à tona o sentimento de infância: o processo de alfabetização acessível à grande parte das pessoas e a educação, necessária para que a tecnologia da leitura e da escrita fosse aprendida. Faltava ainda ressurgir o sentimento de vergonha, que selaria definitivamente o distanciamento entre crianças e adultos.

Nesse contexto, é possível que Rousseau seja o maior expoente, em termos de educação, para nos mostrar a transformação ocorrida na maneira de pensar a infância com o decorrer do tempo. Jean-Jacques Rousseau é filho do agitado e revolucionário século XVIII, e é em um contexto de mudanças sociais, políticas e ideológicas que ele escreve o seu Emílio ou Da educação (1762).

O pensamento rousseauniano é considerado um marco na pedagogia contemporânea e costuma-se dizer que ele provocou uma revolução nessa área, pois o filósofo centraliza a educação nos interesses do aluno, e, mais do que isso, ressalta a singularidade da criança, afirmando que ela não deve ser considerada um adulto em miniatura (ARANHA, 1996).

De fato, já no prefácio do livro Rousseau revela suas críticas à educação que vinha sido dada nas escolas e deixa clara a sua concepção de infância, que viria a influenciar a sociedade como um todo:

Não se conhece a infância: com as falsas ideias que dela temos, quanto mais longe vamos, mais nos extraviamos. Os mais sábios apegam-se ao que importa que saibam os homens, sem considerar que as crianças se acham em estado de aprender. Eles procuram sempre o homem na criança, sem pensar no que esta é, antes de ser homem. (ROUSSEAU, 1973, p.6, grifo nosso).

Rousseau mostra uma maneira completamente nova de ver a criança: com características específicas da infância, que se constitui em uma fase de "aprender". O filósofo defende a infância como fase singular e necessária do desenvolvimento humano, e que deve ser aproveitada para que a criança adquira a força e a inteligência necessárias para a vida adulta. Todas as características que não se têm ao nascer devem ser conseguidas por meio da educação. Contundentemente, afirma que se não passássemos pela infância, com toda a fragilidade que ela representa, a humanidade estaria fadada ao desaparecimento. Segundo o autor:

Se o homem nascesse grande e forte, seu porte e sua força seriam inúteis até que ele tivesse aprendido a deles servir-se. Serlhe-iam prejudiciais, impedindo os outros de pensar em assisti-lo e, abandonado a si 
mesmo, ele morreria de miséria antes de ter conhecido suas necessidades. Deplorase o estado da infância, não se vê que a raça humana teria perecido se o homem começasse sendo criança. Nascemos fracos, precisamos de força, nascemos desprovidos de tudo, temos necessidade de assistência; nascemos estúpidos, precisamos de juízo. Tudo o que não temos ao nascer, e de que precisamos adultos, é-nos dado pela educação. (ROUSSEAU, 1973, p.10).

Emílio traz consigo também um olhar inovador para a educação. Rousseau, como naturalista que é, idealiza formar o homem natural e isso só seria possível se começassem a educar a criança desde o seu nascimento e longe da sociedade, que, segundo o autor, seria corruptora. Uma educação natural, longe dos livros e que recusa o intelectualismo, até que a criança atinja 15 anos, a “idade da razão", período em que a infância possa ser vivida e aproveitada sem que haja a preocupação de aprender o ofício dos pais ou como ser um cidadão. É preciso, antes disso, formar homens que saibam conviver com a dor e que saibam enfrentar as dificuldades da vida.

E o próprio Rousseau, sobre seu método de ensino, afirma:

Na ordem natural, sendo os homens todos iguais, sua vocação comum é o estado de homem; e quem quer seja bem educado para esse, não pode desempenhar-se mal dos que com esse se relacionam. Que se destine meu aluno à carreira militar, à eclesiástica ou à advocacia pouco me importa. Antes da vocação dos pais, a natureza chama-o para a vida humana. Viver é o ofício que lhe quero ensinar. Saindo de minhas mãos, ele não será, concordo, nem magistrado, nem soldado, nem padre; será primeiramente um homem. (ROUSSEAU, 1973, p.15, grifo nosso).
É interessante pensar no quanto Emílio é revolucionário. Ao contrário da sociedade medieval, que "esquecia" as crianças, ou que considerava a infância como fase de transição, que logo seria superada e que justamente por isso não merecia grandes interesses, Rousseau afirma que a educação deve se iniciar já no momento em que a criança nasce, e dedica o primeiro livro inteiro a ensinar às mães e amas os cuidados que devem ter com o bebê que acaba de nascer.

Esses cuidados vão desde a amamentação - Rousseau discorda da amamentação por amas e afirma que essa é uma obrigação das mães -, o zelo ao enfaixar os bebês ou enrolá-los nos cueiros, cuidando para que não se aperte muito os seus membros, e a forma como se atende ou não aos desejos da criança, de modo que elas possam fazer por si mesmas e exijam menos dos outros.

Quanto à iniciação da linguagem, o filósofo nos fala que a única língua natural, comum a todos os homens, são os balbucios que as crianças produzem antes mesmo de falar. Justamente por isso não se faz necessário as amas que "atordoam sem cessar" as crianças com uma "multidão de palavras inúteis a que não compreendem nada senão o tom”. (ROUSSEAU, 1973, p.52).

Rousseau atenta também para a dor. É natural sentir dor, e, na sua concepção, é necessário permitir que as crianças, mesmo na mais tenra idade, conheçam essa sensação.

O destino do homem é sofrer em qualquer época. O próprio cuidado de sua conservação está ligado à dor. Felizes os que só conhecem na infância os males físicos, males bem menos cruéis, bem menos dolorosos do que os outros e que bem mais raramente do que eles nos fazem renunciar à vida! Ninguém se mata com as dores da gota; somente as da alma suscitam o desespero. Temos dó da sorte da infância, mas é da nossa que deveríamos ter. 
Nossos maiores males vêm de nós mesmos. (ROUSSEAU, 1973, p.23).

Por fim, o primeiro livro de Emílio, que tratada primeira infância, é concluído assim:

Os primeiros desenvolvimentos da infância ocorrem quase todos ao mesmo tempo. A criança aprende a falar, a comer, a andar quase ao mesmo tempo. É, em verdade, a primeira fase da sua vida. Antes ela não é nada mais do que era no ventre da sua mãe; não tem nenhum sentimento, nenhuma ideia; mal tem sensações, não sente sequer a sua própria existência. (ROUSSEAU, 1973, p.57).

Esse parágrafo conclusivo nos permite verificar uma situação paradoxal: ao mesmo tempo que Rousseau promove uma quebra de paradigmas, escrevendo um livro inteiro sobre como educar na primeira infância, ele assume aspectos do velho pensamento medieval, ao afirmar que antes de aprender a falar, andar e comer, a criança não é nada mais do que era no ventre de sua mãe. É evidente que seria um erro grotesco comparar o ideário rousseauniano do século XVIII à mentalidade medieval. $\mathrm{O}$ que se pretende mostrar aqui é que, mesmo sendo inovador, ao trazer grande mudança na concepção de infância, Rousseau está em um momento de transição e, muito ainda, haveria de ser repensado em sua teoria, especialmente a partir do final do século XIX e início do século XX.

O segundo livro Rousseau dedica-se à educação de crianças um pouco mais velhas, depois que já aprenderam a falar. É este que o filósofo chama de "segundo período da vida”, quando ele considera que termina a infância.

Já no início, o autor novamente faz duras críticas à antiga maneira de ensinar, fortalecendo sua prática naturalista: “Nossa maneira pedante de educar é sempre a de ensinar às crianças o que aprenderiam muito melhor sozinhas e esquecer o que somente nós poderíamos ensinar" (ROUSSEAU, 1973, p.59). E reitera a sua abominação por ensinar às crianças aquilo que elas podem aprender quando adultas. Não se deve prejudicar a infância antecipando um futuro que é incerto, em um contexto de tantas transformações. O filósofo observa:

Que pensar então dessa educação bárbara que sacrifica o presente a um futuro incerto, que cumula a criança de cadeias de toda a espécie e começa por torná-la miserável a fim de preparar-lhe, ao longe, não sei que pretensa felicidade de que provavelmente não gozará nunca? [...] $\underline{\mathrm{A}}$ idade da alegria passa em meio aos choros, aos castigos, às ameaças, à escravidão (ROUSSEAU, 1973, grifo nosso).

E adverte: “amai a infância, favorecei seus jogos, seus prazeres, seu amável instinto”. (1973, p.61). É necessário deixar que a criança se movimente. Para Rousseau, essa é a maneira encontrada pela natureza para que ela fortaleça e faça crescer o seu corpo. Portanto, devem ser permitidos os pulos, os gritos, a correria, embora seja sempre conveniente duvidar daquilo que a criança não consegue fazer sozinha. "É preciso [...] distinguir com cuidado a necessidade verdadeira da necessidade de fantasia”. (p.69).

Outro ponto marcante no segundo livro, Emílio, é a crítica ao "uso da razão” com crianças pequenas, em virtude do fato de que o homem, para o autor, não se reduz à dimensão intelectual, como se a natureza pudesse ser apenas razão e reflexão. Isso fica muito claro quando afirma:

De todas as faculdades do homem, a razão, que não é, por assim dizer, senão um composto de todas as outras, é a que se 
desenvolve mais dificilmente e mais tarde. E é dessa que se querem servir para desenvolver as primeiras! A obra-prima de uma boa educação está em fazer um homem razoável: e pretende-se educar uma criança pela razão! É começar pelo fim, é querer fazer o instrumento com a obra. Se a criança entendesse razão, não teria necessidade de ser educada. (ROUSSEAU, 1973, p.74)

\section{O autor acrescenta:}

A natureza quer que as crianças sejam crianças antes de ser homens. Se quisermos perturbar essa ordem, produziremos frutos precoces, que não terão maturação nem sabor e não tardarão em corromper-se; teremos jovens doutores e crianças velhas. A infância tem maneiras de ver, de pensar, de sentir, que lhes são próprias; nada menos sensato do que querer substituí-las pelas nossas (ROUSSEAU, 1973, p.75, grifo nosso).

Entretanto, o fato de Rousseau não reduzir a educação ao intelectualismo não quer dizer que ele acredite que as crianças não são capazes de raciocinar. Ao contrário, para o autor, as crianças raciocinam muito bem, mas a respeito daquilo que conhecem e do que faz parte de seus interesses. $O$ grande erro da escola está em levá-las a pensar sobre aquilo que não compreendem.

Outra preocupação é "preservar o coração das crianças do vício e seu espírito do erro" (p.80). É necessário que isso seja feito antes que ela atinja a idade de 12 anos, já que depois disso essas "raízes são tão profundas que já se faz impossível arrancá-las” (p.79).

É importante ressaltar a opinião de Rousseau no que diz respeito à leitura e aos livros. Postman (1999) se apoia em uma afirmação do autor para argumentar que a alfabetização é um dos mecanismos encontrados pela sociedade moderna para distanciar adultos e crianças. Postman enfatiza:
Tirando assim todos os deveres da criança, tiro os instrumentos de sua maior miséria, isto é, os livros. A leitura é o flagelo das crianças e quase a única ocupação que sabem dar-lhes. Somente aos 12 anos Emílio saberá o que seja um livro. Mas é preciso, ao menos, dirão, que saiba ler. Concordo: é preciso que saiba ler quando a leitura lhe for útil; até então ela só servirá para aborrecê-lo. (1999, p.110, grifo nosso).

Se, corroborando a opinião de Postman, concebermos que por meio da leitura a criança tem acesso aos segredos dos adultos e que, a partir dela, pode conhecer tudo o que existe, a objeção de Rousseau é prudente e, por ele, a infância não terminaria antes dos 12 anos. Rousseau (1973, p.164) afirma que a criança deve ser respeitada dentro das suas próprias características. E não cabe a ninguém antecipar capacidades que podem e devem ser adquiridas à medida que a natureza permita e as tornem necessárias.

Embora boa parte daquilo que Rousseau recomenda esteja no campo da utopia, seu pensamento é realmente revolucionário. Ele considera a infância como uma fase singular, com necessidades e características próprias. Mais do que isso, atribui um tratamento todo especial a essa fase de desenvolvimento, que não deve ser maculada com os vícios e hábitos dos adultos, mas, ao contrário, deve ser apreendida em suas particularidades.

A revolução copernicana que muitos acreditam que Rousseau tenha provocado na pedagogia mudou radicalmente o modo de se pensar a criança em seu tempo e inspirou muitos educadores das décadas seguintes.

A partir do século XIX, a infância alcançou um lugar de destaque na sociedade, ao passo que inúmeros estudiosos dedicaram-se a pesquisar sobre o melhor método de ensino, a educação que fosse voltada para 
os interesses do aluno, a educação com função social e que fosse acessível a todos, independentemente de classe social. A criança deixa de ser o mal a ser superado e passa a ser percebida como a sementinha do bem. Nesse contexto, surgem novos pesquisadores da infância, como Pestalozzi, Fröebel, Dewey, Montessori e Freinet, todos influenciados pelas ideias rousseaunianas.

Heinrich Pestalozzi compartilha com Rousseau o ideal iluminista sobre a bondade natural do homem, bem como a crença de que a educação deve ter como fim o desenvolvimento das capacidades da criança em um ambiente de liberdade. Acredita na individualidade de cada ser humano e afirma que ela é a condição necessária para se alcançar a virtude.

Pestalozzi (apud GILES, 1987, p.191) sustenta a ideia de que

[...] cada indivíduo nasce com faculdades preexistentes. A mãe e o mestre devem contentar-se em desenvolver essas faculdades inatas. [...] a criança é dotada de todas as faculdades da natureza humana, mas nenhuma dessas faculdades encontra-se desenvolvida, pois cada uma é como um botão que ainda não desabrochou. Quando o botão desabrocha, cada uma das folhas se abre, nenhuma permanece fechada. É esse mesmo caminho que o processo educativo deve seguir, pois a própria criança é semelhante à semente que cresce devagar, imperceptivelmente, até chegar à maturidade.

Sua grande preocupação serão as crianças menos favorecidas, e, quanto a isso, alerta que a "as faculdades do homem devem ser cultivadas de tal maneira que nenhum homem possa dominar o outro, mas que cada um possa realizar suas potencialidades" (GILES, 1987, p.192, grifo nosso). O traço marcante de Pestalozzi é "a equiparação da instituição educacional ao lar, ambas envoltas de singeleza e naturalidade" (p.192).

O educador também ficou conhecido como o "educador da humanidade". Ele compartilhava a ideia de democracia disseminada por Rousseau, buscando a melhoria no quadro de miséria da sociedade alemã, tomando medidas tais como: criação de escolas na zona rural com foco no aprendizado de ofícios; oposição aos métodos tradicionais, evidenciando que a criança seria um agente ativo na educação, tomando para isso o conceito de ação que "significa, para ele: observação, investigação, coleta de material e experimentação" (DROUET, 1988, p.12).

Friedrich Fröebel segue o mesmo caminho de Pestalozzi, até porque sua experiência de aprendizagem no magistério se deu sob a orientação do mesmo, em Yverdon. Entretanto, considera o trabalho do mestre "simplista demais, empírico demais e até arbitrário” (GILES, 1987, p.200), e, assim, vai aperfeiçoar suas ideias com o objetivo de criar uma concepção própria de ensino e de infância. Fröebel foi um dos primeiros educadores a se preocupar com crianças em idade inferior às matriculadas no ensino elementar e essa foi a sua principal contribuição pedagógica.

Mais um aspecto que merece consideração é a criação do pressuposto de que não se pode negar condições e momentos de desenvolvimento à criança, haja vista que ela pode ser prejudicada nas etapas subsequentes de sua formação. Fröebel destacou-se com sua didática, que era permeada pelo amor e por suas criações inovadoras como forma de aprendizado; ele considerava que os jogos tinham papel fundamental nos jardins de infância, pois contribuíam para o desenvolvimento físico, intelectual e moral da criança.

A relevância de seu trabalho permanece clara todas as vezes que passamos em frente a um jardim de infância. Os kindergarten 
(jardins de infância, em alemão) criados por Fröebel demonstram a continuidade da obra de Pestalozzi. Como seu mestre, Friedrich Fröebel também considera a criança como uma sementinha que precisa ser cuidada para crescer e se desenvolver.

Da mesma forma, Maria Montessori concebe a criança como sementinha a germinar e acredita que a educação deve favorecer o processo seu desenvolvimento natural. Foi a primeira educadora da pré-escola moderna. Iniciou seus estudos como psiquiatra de crianças especiais, criando para essas crianças "materiais coloridos, facilmente manipuláveis, pois defendia a ideia de que elas deveriam construir suas aprendizagens a partir do que existia em seus ambientes" (VALLE, 2010, p.21).

Para a médica italiana, se a criança for colocada em um ambiente livre, rico e apropriado, com materiais interessantes que favoreçam a realização de atividades espontâneas, terá melhores condições de desenvolver sua personalidade e a autoeducação.

Montessori trouxe uma grande inovação ao criar uma escola onde tudo fosse em tamanho apropriado para crianças em fase de crescimento, ao passo que o mais importante era identificar as verdadeiras necessidades da infância, pois mesmo as tarefas mais simples deveriam ser consideradas como veículos de aprendizagem.

Outra contribuição da médica foi a noção da criança como "ser absorvente". Para Giles (1987), a criança absorve e incorpora as experiências do meio ambiente de forma natural. Isso trouxe uma grande transformação na forma de pensar a criança, especialmente nos anos iniciais da infância, que passara a ser o período mais importante de desenvolvimento, posto que é nele que se desenvolve o caráter.

Essa concepção de desenvolvimento infantil é decorrente de uma concepção epistemológica da vertente apriorista ou inatista. Nessa perspectiva, a infância constitui uma etapa do desenvolvimento da criança, que fluirá naturalmente, haja vista que a pessoa já nasce com o conhecimento na sua carga genética e o mínimo de mediação possível é necessária para que esse conhecimento seja desenvolvido.

Montessori defendeu o conceito de educação da vontade e da atenção. Este método permite às crianças escolher o material, pois, nessa etapa, ela aprende mais pelas ações do que pelas palavras. Até hoje a concepção montessoriana é utilizada em instituições de ensino no mundo todo.

Por sua vez, o educador John Dewey, em uma perspectiva diferente, traz uma educação para a democracia, onde as crianças sejam educadas para participar ativamente da sociedade na qual vivem e não para serem "escravas". Entretanto, na mesma linha dos estudiosos citados anteriormente, Dewey (apud GILES, 1987, p.262) afirma que "deve-se animar o aluno a seguir suas tendências 'naturais', a procurar, inquirir, explorar e integra-se ao meio ambiente; a aprender a partir da experiência. É só esse processo que leva o aluno a crescer".

Para o teórico, a educação não pode estar afastada da vida em sociedade e o processo educativo deve ser visto como sinônimo do processo democrático. Ele propôs o método científico, que focaliza as experiências, de modo que desde a infância a criança compartilhe com os demais suas descobertas, com a finalidade de socialização de conhecimentos. Defendia que tudo aquilo que é feito e praticado pelo ser humano é apreendido com mais rapidez, fazendo do aluno o autor de seu próprio desenvolvimento.

Conforme Giles (1987, p.262), “a moral e os valores são apreendidos dentro de um determinado contexto social através da observância de regras apropriadas, e essas 
emergem de experiências coletivamente partilhadas”. Dessa forma, Dewey amplia o papel do professor, que outrora interferia o mínimo possível para que o desenvolvimento da criança ocorresse de forma natural e livre, mas que agora é responsável por ajudar o aluno a aprender os valores necessários para a participação ativa em uma democracia e a desenvolver em si a capacidade criativa. Com isso, o professor tem o compromisso de elaborar planos de ação e disponibilizar recursos e meios necessários para a execução da aula.

Nesse sentido, a educação jamais deve levar em consideração somente o aluno, mas também a comunidade e o meio ambiente. A educação também não deve ser uma preparação para a vida, mas sim a própria vida.

A principal contribuição pedagogia de Dewey, segundo Aranha (1996, p.171) é no que diz respeito ao interesse,

[...] o esforço e a disciplina são para ele produtos do interesse. Por isso é importante para o educador a descoberta dos reais interesse da criança e só avançar na ampliação de seus poderes apoiando-se nesses interesses. Apenas assim a experiência adquire valor educativo e não se reduz a um artificialismo inócuo.

Mais próximo da nossa realidade, Célestin Freinet também trouxe contribuições para o modo de pensar a infância e a educação das crianças. Corroborando a visão de Dewey, aposta em uma educação que tenha como princípio a vida das crianças. Nesse sentido, criou as aulas-passeio, em que os alunos poderiam estar em contato com a natureza e com a sociedade, e o livro da vida, no qual as crianças poderiam escrever suas descobertas e experiências. Freinet acreditava que conteúdos e conceitos de diferentes áreas deveriam ser trabalhados de maneira integrada para que despertassem o interesse e a curiosidade das crianças.
Para esse educador francês, a aprendizagem através da experiência é a mais eficaz. No entanto, o aluno avança em seus experimentos com a cooperação do professor. Desse modo, fica claro que a interação professor-aluno é essencial para a aprendizagem. Mas, para que essa interação seja bem-sucedida, é necessário que o professor considere o conhecimento já existente do aluno. Da mesma forma, é fundamental que ele conheça a realidade em que vive o aluno. Freinet entende que a força motriz do processo educativo deve ser o trabalho. Por meio dele, o indivíduo descobre e exerce seu poder. Além disso, o trabalho garante que todo o aprendizado passe pela experiência da vida, integrando, assim, teoria e prática.

Tanto Dewey quanto Freinet se apropriam da concepção apriorista de infância, mas a complementam com uma percepção empirista de transmissão cultural, criando uma nova óptica de integração homem-meio. Essa concepção está muito próxima do paradigma contemporâneo da Educação Infantil, que destaca no pensamento e na linguagem, na interação e na mediação a tônica pedagógica e educativa, reconhecendo a criança como sujeito singular e de direitos.

Depois de uma longa caminhada histórica, finalmente chegamos a um conceito mais próximo daquele que temos atualmente da infância, segundo o qual a criança é concebida como um sujeito histórico, que produz e reproduz uma cultura própria e singular e a educação é tida como um meio emancipatório e transformador para que, pouco a pouco, a criança se liberte da dependência do adulto.

\section{Referências}

ARANHA, M. L. A. Filosofia da educação. 2.ed. São Paulo: Moderna, 1996. 
ARIÈS, P. História social da criança e da família. Rio de Janeiro: Zahar Editores, 1973.

CASTELLO, L. A.; MÁRSICO, C. T. Oculto nas palavras: dicionário etimológico de termos usuais na práxis docente. Belo Horizonte: Autêntica, 2007.

DROUET, R. C. R. Fundamentos da educação pré-escolar. São Paulo: Ática, 1988.

GILES, T. R. História da educação. São Paulo: E.P.U., 1987.

HEYWOOD, C. Uma história infantil. Porto Alegre: Artes Médicas, 2004.

POSTMAN, N. O desaparecimento da infância. Rio de Janeiro: Graphia, 1999.

REDIN, E. et al. (Orgs.). Infâncias: cidades e escolas amigas das crianças. Porto Alegre: Mediação, 2007.

ROUSSEAU, J.-J. Emílio ou Da Educação. Difel, 1973.

SARMENTO, M. A globalização e a infância: impactos na condição social e na escolarização. In: GARCIA, R. L.; LEITE, A. F. (Orgs.). Em defesa da educação infantil. Rio de Janeiro: DPEA, 2001.

VALLE, L. R. L. D. Fundamentos da educação infantil. Curitiba: Fael, 2010.

Enviado em: 17/06/2013

Aceito em: 27/07/2013 